\title{
Experience in Application of Rational-Emotive Therapy in Psychological Assistance to Women with Eating Disorders
}

\author{
${ }^{1}$ Elena Yu. Shpakovskaya, ${ }^{2}$ Natal'ya G. Bazhenova, ${ }^{3}$ Oksana V. Tokar, ${ }^{4}$ Oksana P. Chernykh \\ 1,2,3 Nosov Magnitogorsk State Technical University, 38 Lenin Avenue, 455000, Chelyabinsk Region, Magnitogorsk, \\ Russia \\ ${ }^{4}$ Moscow University of Finance and Law MFUA, 17/1 Serpukhov Val Str., 115191, Moscow, Russia. \\ Email: info@ores.su
}

Received: 22 ${ }^{\text {nd }}$ June 2018, Accepted: 01 ${ }^{\text {st }}$ August 2018, Published: 31 ${ }^{\text {st }}$ August 2018

\begin{abstract}
This paper deals with the experience of using rationalemotive therapy in psychological assistance to women with eating disorders. Psychodiagnostic, experimental and statistical methods of research are used. The results of the author's psychological assistance program "In harmony with oneself" are presented with the use of the rational-emotive therapy methodology. The purpose of the program: therapy of eating disorders and normalization of the body mass index of women. Targets of psychotherapeutic influence are indicated: goals and irrational attitudes, psychoemotional tension, bodily image of "ego", rigidity of psychological defenses. The results of approbation of the program are ascertained: normalization of the body mass index and types of eating behavior, preservation of positive dynamics within six months after the end of therapy. The ways of further improvement of the program are planned taking into account the experience gained in applying rational-emotive therapy.
\end{abstract}

Keywords: Eating Behavior, Eating Disorders, Body Mass Index, Emotional Type of Eating Behavior, Restrictive Type of Eating Behavior, External Type of Eating Behavior, Psychological Defenses, Obligation towards Oneself, Obligation towards Others, Catastrophizing, Frustration Tolerance, Image of Corporal "ego", Psychological Therapy of Eating Behavior; Rational-Emotive Therapy.

\section{Introduction \\ Introduction to the problem}

Modern trends in food behavior of the population are characterized, on the one hand, by the desire for an ideal shape, the image of which is largely determined by the media, and on the other hand, by an unbalanced diet. As a result, we are confronted with an extreme eating disorders leading to a change in body weight towards obesity or painful leanness. Disturbance of eating behavior involves changing eating habits, constant weight control and fears about its increase, denial of the existence of a weight problem, worsening of somatic health and psychosocial functioning
(Skugarevskii O.A., 2007, p.76-85; Tumbasova E.R., 2017, p.130-133).

Relevance of the problem

The importance of the research is dictated by practical tasks related to the organization of the process of psychological support to persons with disturbed eating behavior and a deviating body mass index (hereinafter BMI); advancing of the level of professional and psychological training of specialists in the educational and social spheres, as well as in the sphere of health; the development of educational programs for the prevention of eating disorders in different sex and age groups of the population (Bazhenova N.G., 2015., p.25-29., Tokar O.V., Shpakovskaia E.Iu., 2016, p.524).

\section{Study of the problem}

The current approaches to the implementation of psychological assistance to people with eating disorders have several directions: cognitivebehavioral psychotherapy (Merphy R., Straebler S., Cooper Z., 2010; Malkina-Pykh IG, 2007, etc.); systemic family psychotherapy (Minuchin S. Rosman B.L. \& Baker L., 1978, Geist R., Heineman M., Stephens D. et al, 2000, etc.); body-oriented psychotherapy (Lowen A., 1998; Rybalko M.I., 2005; Malkina-Pykh I.G., 2007; Kultyshev D.V., 2010, etc.); transpersonal model of psychotherapy (Prilenskaia A.V., 2009); rational-emotional therapy (Beck A.T., 1976; Ellis A., 2001;); as well as a combination of approaches and techniques in dealing with specific types of eating disorders (Gavrilov V.A., 1999; Gurevich I.N., 1997; Voznesenskaia T.G., Safonova V.A., Platonova N.M., 2000, Kareva M.A., 1993; Korkina M.V., Tsivilko M.A., 1995; Markov A.A., 2007; Prilenskaia A.V., 2006; Rotov A.V., 2000; Taton Ia., 2008; Fedorova I.I., 2007; Iaremenko L.N., 2002).

The researchers drawing on the typology proposed by the authors of the Dutch Eating Behavior Questionnaire suggest building psychological counseling in accordance with the leading type of eating behavior: clients with an emotion-like type of behavior (hereinafter - emotiogenic EB) are suggested to work in the context of resolving internal conflicts and harmonizing the sensory sphere; the external type 
(hereinafter referred to as the external EB) needs to be aware of and reworking its habits in the field of eating behavior, being proposed for this purpose to use cognitive-behavioral therapy; restrictive type (hereinafter - restrictive EB) should, first of all, acquire adequate dietary knowledge and based on it rebuild their eating behavior (Sidorov A.V., 2012. p.25-26).

One of the methodological approaches to work with eating disorders is rational-emotive therapy (hereinafter RET).

RET is based on the theoretical concept of mediation of the ABC model (A. Ellis, 1998), according to which a negative emotional state or behavior is caused not by an event, but by a system of human interpretations relating certain life events and situations to certain categories. Activating Events (A) that take place in a person's life contribute to the formation of emotional and behavioral disorders, or Consequences (C), mainly through our Beliefs (B) about these events, i.e. positively or negatively colored thoughts have a significant effect on the development of emotional and behavioral disorders, and a change in the way of thinking can help overcome these disorders. The formation of irrational attitudes occurs in the process of internalization of social experience, and, in many respects, due to the huge number of stereotypes broadcasted by the family, the media, reference groups and other socialization institutions.

The extended $\mathrm{ABC}$ model includes an additional characteristic G, indicating the goals, values and desires that people bring to the ABC system. These goals, in fact, are the context in which people perceive events, and evaluate the world around them. Goals G interact and influence all elements of the ABC system. These relationships can be functional or dysfunctional and disharmonious.

In relation to our research, $\mathrm{G}$ includes goals, values, intentions, stereotypes related to eating and attitude to food, forming irrational attitudes towards oneself, other people and life events (B), leading to eating disorders in the form of either restrictive or emotiogenic, or external variants of manifestation (C). RET emphasizes that a systemic approach to the relationship and interaction of Activating Events (A), Beliefs (B), and emotional and behavioral Consequences $(\mathrm{C})$, which manifests itself in healthy and unhealthy people, should be particularly important.

\section{Hypotheses}

The hypothesis of the study was the following: women with eating disorders are characterized by a high level of neuroticism, a negative bodily image of their "ego", expressed by irrational attitudes, the prevalence of negation and regression in the psychological defense system; these psychological characteristics are the determinants of eating disorders; the application of rational-emotional therapy will contribute to the constructive transformation of goals, irrational attitudes, psycho-emotional stress, the body image of "ego", and psychological defenses.

\section{Methods}

Drawing on the purpose and objectives of the study, we have formed a general sample, which included 112 girls and women aged 16 to 30 years, with 86 subjects being further selected therefrom by the indicators of full participation. The participants of the experiment were Internet users visiting groups and sites devoted to the problems of body weight: "Typical anorexic," "Anorexia Psychology", "Anorexia", "Khudoba," "No Excess Weight!", "Khudelka", "Losing Weight Diary" , "Weight Management", "Your Trainer", "On Scales", etc. The average age of the respondents was 23 years. The differentiation of the respondents into groups was based on the results of calculating the "Quetelet mass index", which is calculated by the formula:

$$
I=\frac{m}{h^{2}} ; \text { where: } \mathrm{m} \text { - body mass in }
$$

kilograms; $\mathrm{h}$ - height in meters $\left(\mathrm{kg} / \mathrm{m}^{2}\right)$.

The present experiment considers normal the body weight at which the BMI is at least 18.5 and does not exceed 25 . The obesity is the BMI exceeding 30 , and the BMI from 16 to 18.5 indicates a deficiency in body weight.

Based on these questionnaires, we have formed two groups of respondents:

1. Sample A (41 people) - girls and women with BMI within normal range.

2. Sample B (45 people) - girls and women with BMI upward (obesity) (sample B1, 21 people), and downward (deficit mass) (sample B2, 24 people) deflection.

All respondents have some type of eating disorders. A number of respondents have mixed types of eating disorders.

To implement the research goal, we used the following set of techniques:

1. Dutch Eating Behavior Questionnaire DEBQ, 1986, identifies the types of eating disorders in the subjects (emotional, restrictive, external) (Malkina-Pykh I.G., 2007. p.261-265).

2. Eating Disorder Inventory (EDI, 1983, D.M. Garner, M.P. Olmstead, J.P. Polivy) (adapted by O.A. Ilchik, S.V. Sivukh, O.A. Skugarevskii, S. Suihi) aimed at finding out eating disorders (anorexia nervosa and bulimia); includes seven scales: the desire for leanness, bulimia, dissatisfaction with the body, inefficiency, perfectionism, distrust in interpersonal relations, and interoceptive incompetence (Ilchik OA, 2011. p.39-50). 
3. "Express diagnostics of the level of neuroticism" (LN), 1999, Bechterew NIPNI, based of the "neuroticization" scale of the UNP questionnaire, which determines the level of neuroticism of respondents (Fetiskin N.P. et al., 2002. p.399-400).

4. "Diagnostics of typologies of psychological protection" (R.Pluchik, G.Kellerman, H.R.Conthe, adapted by E.S. Romanova, L.R. Grebennikov) (Life Style Index, LSI), revealing in respondents their leading psychological protection: negation, displacement, regression, compensation, projection, replacement, intellectualization, and reactive formations (Shpakovskaia E.Iu. et al., 2007. p.117-124).

5. "Body Ego Diagnostics" by I.V. Lybko (2008, under A.S. Pushkin Brest State University), studying the image of the physical ego, questions of self-relationship of the personality of the subjects and their self-perception (Lybko IV, 2008. p.5-21).

6. "Method for diagnosing the presence and severity of irrational attitudes" by A. Ellis (1955,
Founder of rational-emotive therapy RET) - in order to determine the degree of rationality/irrationality of thinking, the presence and severity of irrational attitudes of respondents, including the following scales: catastrophizing, obligation towards oneself, obligation towards others and an appraisal attitude (Kameniukin, Kovpak, 2008. p. 201-206).

In order to prove the reliability of the obtained results of the study, we also used methods of mathematical statistics: the identification of differences in the distribution of the trait (Student t-test); revealing of the degree of consistency of the studied measurements of two characteristics (regression analysis).

\section{Main Part}

A comparative analysis of the results of the study using the methodology of the "Dutch Eating Behavior Questionnaire" in the samples of respondents with normal and deviating BMI showed that there are significant differences in all the scales considered by us (Table 1).

\begin{tabular}{|c|c|c|c|}
\hline \multirow[t]{2}{*}{ Method } & \multirow[t]{2}{*}{ Method scale } & \multicolumn{2}{|c|}{ Student t-test } \\
\hline & & $\begin{array}{c}\text { Sample A (normal } \\
\text { BMI) and B } \\
\text { (deviating BMI) }\end{array}$ & $\begin{array}{c}\text { Sample B1 (high } \\
\text { BMI) and B2 } \\
\text { (low BMI) }\end{array}$ \\
\hline \multirow{3}{*}{$\begin{array}{l}\text { Dutch Eating Behavior } \\
\text { Questionnaire }\end{array}$} & Emotiogenic EB & 3.01** & 1.30 \\
\hline & Restrictive EB & $2.08 *$ & $2.31 *$ \\
\hline & External EB & $2.10 *$ & $2.91 * *$ \\
\hline \multirow[t]{7}{*}{ Eating Behavior Assessment Scale } & Desire for leanness & 1.45 & 0.96 \\
\hline & Bulimia & 1.52 & $2.42 *$ \\
\hline & Dissatisfaction with body & $3.54 * *$ & 1.63 \\
\hline & Inefficiency & $2.27 *$ & $2.15 *$ \\
\hline & Perfectionism & 2.05* & 1.34 \\
\hline & $\begin{array}{l}\text { Distrust in interpersonal } \\
\text { relations }\end{array}$ & 1.25 & 1.53 \\
\hline & Interceptive incompetence & 2.58* & 2.06* \\
\hline Express diagnosis of LN & Level of neuroticism & $3.26 * *$ & 1.93 \\
\hline \multirow{9}{*}{$\begin{array}{l}\text { Diagnostics of typologies of } \\
\text { psychological defense }\end{array}$} & Negation & $3.57 * *$ & 2.01 \\
\hline & Repression & 2.01 & 1.84 \\
\hline & Regression & 3.04** & $2.63 *$ \\
\hline & Compensation & 2.71* & 1.45 \\
\hline & Projection & 1.94 & 2.05 \\
\hline & Substitution & $2.86 * *$ & 1.32 \\
\hline & Intellectualization & 1.25 & 2.03 \\
\hline & Reactive formations & $3.12 * *$ & 0.96 \\
\hline & $\begin{array}{l}\text { Index of intensity of } \\
\text { psychological defenses }\end{array}$ & $3.42 * *$ & 1.83 \\
\hline \multirow[t]{2}{*}{ Body ego diagnostics } & $\begin{array}{l}\text { Self-acceptance of the image } \\
\text { of the body ego }\end{array}$ & $2.48^{*}$ & 1.48 \\
\hline & $\begin{array}{l}\text { The influence of the other on } \\
\text { the attitude toward the image } \\
\text { of the body ego }\end{array}$ & $2.62 *$ & 1.60 \\
\hline \multirow{3}{*}{$\begin{array}{l}\text { Methods of diagnosing irrational } \\
\text { attitudes }\end{array}$} & Catastrophizing & $3.51 * *$ & 0.82 \\
\hline & Obligation toward oneself & $3.58 * *$ & $2.33 *$ \\
\hline & Obligation toward others & $2.35 *$ & $2.51 *$ \\
\hline
\end{tabular}


Helix Vol. 8(5): 3673- 3681

\begin{tabular}{|l|l|l|l|}
\hline & Low frustration tolerance & $\mathbf{2 . 0 7} *$ & 2.04 \\
\cline { 2 - 4 } & Self-assessment & 1.86 & 1.95 \\
\cline { 2 - 4 } & & $\begin{array}{l}* t_{t}=2.02, \mathrm{p} \leq 0.05 ; * * \\
t_{t}=2.69, \mathrm{p} \leq 0.01 ;\end{array}$ & $\begin{array}{l}* t_{t}=2.06, \mathrm{p} \leq 0.05 ; \\
* * t_{t}=2.80, \\
\mathrm{p} \leq 0.01 ;\end{array}$ \\
\hline
\end{tabular}

Table 1: Reliability of Differences in the Groups of Respondents in Terms of Measurable Indicators of Food Behavior, The Level of Neuroticism, Psychological Defenses, The Image of the Body Ego and Irrational Attitudes

A comparative analysis of the results of the study both of samples A (normal BMI) and B (deviating BMI) showed statistically significant differences in all the types of eating behavior considered (emotional, restrictive and external), and of the scale of eating behavior: dissatisfaction with the body, inefficiency, perfectionism, interceptive incompetence; significant differences in the level of neuroticism in these samples, significant differences in the application of the following psychological defenses: negation, regression, compensation, substitution, reactive formations and the following irrational attitudes: catastrophic, self-imposed and others and low frustration tolerance; as well as significant differences in the self-acceptance of the body image of ego and the influence of the other on the attitude to the image of the body image of ego.

A comparative analysis of the results of the study of samples B1 and B2 showed the following picture of significant differences: for external $\mathrm{EB}$ and restrictive EB; for the scales "bulimia", "inefficiency" and "interceptive incompetence"; in terms of psychological defense - for the scale of "regression", irrational attitudes - for the scales of "obligation toward oneself" and "obligation toward others".

In order to construct the strategy and tactics of influencing the disturbed eating behavior, we conducted a regression analysis that allowed us to determine the targets of the psychotherapeutic effect (Table 2)

\begin{tabular}{|c|c|c|c|c|c|c|c|c|c|c|}
\hline \multirow[b]{2}{*}{ Method scales } & \multicolumn{3}{|c|}{$\begin{array}{l}\text { Dutch Eating Behavior } \\
\text { Questionnaire (scales) }\end{array}$} & \multicolumn{7}{|c|}{$\begin{array}{l}\text { Eating Behavior Assessment Scale } \\
\text { (scales) }\end{array}$} \\
\hline & 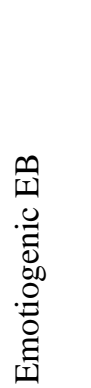 & 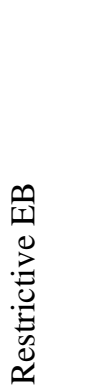 & 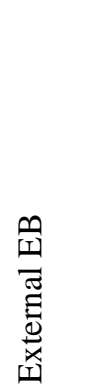 & 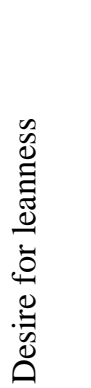 & 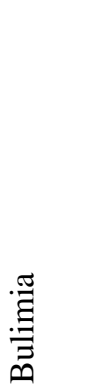 & 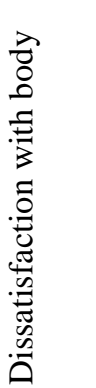 & 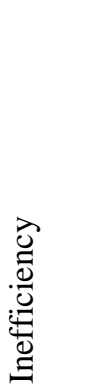 & 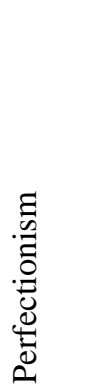 & 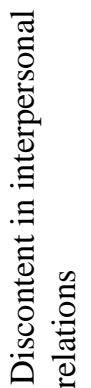 & 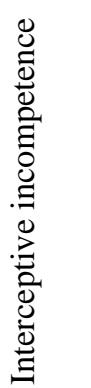 \\
\hline Level of neuroticism & 0.52 & 0.32 & 0.30 & 0.73 & 0.69 & 0.54 & 0.24 & 0.31 & - & - \\
\hline Negation & 0.56 & 0.84 & 0.45 & 0.28 & 0.31 & - & - & - & - & - \\
\hline Regression & - & - & 0.41 & - & 0.64 & - & - & - & - & 0.34 \\
\hline Compensation & 0.64 & 0.48 & - & 0.65 & 0.71 & - & - & 0.68 & & \\
\hline Substitution & 0.72 & 0.61 & - & 0.45 & 0.49 & 0.51 & - & - & - & - \\
\hline Reactive formations & - & - & - & 0.59 & 0.68 & - & - & 0.71 & - & - \\
\hline $\begin{array}{l}\text { Self-acceptance of } \\
\text { the image of the } \\
\text { body ego }\end{array}$ & 0.67 & 0.98 & - & 0.31 & 0.43 & 0.52 & - & - & - & - \\
\hline $\begin{array}{l}\text { The influence of the } \\
\text { other on the attitude } \\
\text { toward the image of } \\
\text { the body ego }\end{array}$ & - & 0.68 & - & 0.69 & 0.56 & 0.72 & - & - & - & - \\
\hline Catastrophizing & 0.79 & 0.68 & 0.58 & 0.52 & 0.45 & 0.76 & 0.65 & - & - & - \\
\hline $\begin{array}{l}\text { Obligation toward } \\
\text { oneself }\end{array}$ & 0.65 & 0.72 & - & 0.49 & 0.51 & 0.67 & 0.43 & 0.61 & - & - \\
\hline
\end{tabular}


Helix Vol. 8(5): 3673- 3681

\begin{tabular}{|l|c|c|c|c|c|c|c|c|c|c|}
\hline $\begin{array}{l}\text { Obligation toward } \\
\text { others }\end{array}$ & 0.24 & - & 0.15 & 0.31 & 0.37 & -0.43 & - & - & - & - \\
\hline $\begin{array}{l}\text { Low frustration } \\
\text { tolerance }\end{array}$ & 0.64 & 0.52 & 0.58 & 0.43 & 0.49 & 0.67 & 0.41 & - & 0.54 & - \\
\hline
\end{tabular}

Table 2: Results of Regression Analysis in the Group with a Deviating BMI (Significant Regression Coefficients are Indicated)

Emotiogenic EB is influenced by a high level of neuroticism, psychological defenses of negation, compensation, substitution; this type of EB shows low results in self-acceptance of the body ego and uses more such irrational settings as disastrous, obligation toward others and oneself and low frustration tolerance.

Respondents with restrictive EB have high rates of neuroticism, they are more likely to use psychological defenses of negation, substitution and compensation; less accept the image of the body ego and are subject to the influence of others on its formation; the following irrational attitudes are typical for them: catastrophic, obligation toward oneself, low frustration tolerance.

Respondents with external EB also, like the previous two, show a high level of neurotic personality; as a psychological defense they use negation and regression; the following irrational attitudes are typical for them: catastrophizing, obligation toward others, and low frustration tolerance.

Revealing the trends of psychological features of women with eating disorders and deviating BMI served as the basis for the development of a psychological assistance program "In harmony with oneself". The goal is to treat disturbed eating behavior and normalize the BMI of the program participants. The program is focused on the comprehensive implementation of a variety of methods and forms of work on the therapy of cognitive, emotional and behavioral areas: working together with a dietician to form knowledge and habits of healthy eating; attending classes on bodily-oriented therapy aimed at understanding and accepting the image of body ego; group psychotherapeutic work using the RET.

The choice of means of psychotherapeutic intervention was built subject to the psychological characteristics of women with eating disorders and the results obtained in the course of the study, as well as literary recommendations on the psychotherapy of eating disorders. The general strategy of psychotherapeutic treatment for eating disorders we have developed was reflected in programs that assume a differentiated approach to working with women with high and low BMI. The program is modular in nature: module 1 - "Principles of Balanced Nutrition", module 2 - "Body-Oriented Therapy", and module 3 "Rationally-Emotive Therapy". The implementation of the modules was carried out in parallel throughout the life of the program. The type of eating disorders was the basis for the differentiation of respondents in the development of the "Principles of Balanced Nutrition" module at the initial stages of its implementation. The work on the other two modules was carried out only taking into account BMI, which allowed to implement the prevention of the transformation of some nutritional disorders into others, thanks to the group dynamics, the possibility of accumulating different opinions, assessments and experience in heterogeneous groups, and also due to the therapeutic effects of the group.

Duration of work with each group under the program "In Harmony with Oneself" was 20 weeks, 3 lessons per week, duration of each lesson - 3 hours (three modules).

This paper presents the experience of using one module of the program "In Harmony with Oneself" module 3. "Rationally-Emotive Therapy". The goal of RET is the correction of irrational attitude related to eating behavior. The techniques of RET were used during the whole period of the group's work, in parallel with other forms and content of the work. The amount of the hours for RET-80. The results of the diagnostics of irrational attitudes dictated the need for a differentiated implementation of RET in the group of women with low BMI and in the group with high BMI. In the process of treating eating disorders, it was necessary to use a differentiated approach, taking into account the system of attitudes of women in relation to themselves, surrounding people and life situations, the nature of the manifestations of psychological characteristics, the style of a protective response to behavior change in relation to food irritants and stress reactions with the formation of more adequate mechanisms of mental adaptation and the use of adaptive behaviors through the use of personal and environmental resources.

The main principle of the program is the development of skills of self-regulation of eating behavior, involving the training of women in a number of techniques that enable them to cope with newly emerging negative experiences and life problems. In fact, women become their own psychotherapists. We set the task of forming such an attitude system, a way of thinking, knowledge and skills that would allow us to implement adaptive and effective eating behavior even after the official completion of the program. 


\section{Helix Vol. 8(5): 3673- 3681}

Based on the results of the diagnostic study and the identification of factors and mechanisms of the formation of eating disorders, the following targets of RET-based psychotherapeutic treatment were selected: goals and irrational attitudes, psychoemotional stress, body ego, rigidity of psychological defenses.

The RET was implemented gradually:

1. Establishment of confidential therapeutic relations with and within the group.

2. Introduction of the group members to the RET concept. At this stage, women get a general idea of how thoughts and attitudes affect emotions and behavior.

3. Awareness and identification of irrational attitudes. This stage sets itself the task of teaching members of the group to track and recognize their cognitions (both in figurative and verbal forms), and record them. The analysis of identified irrational settings makes it possible to introduce dissonance into the attitude system associated with food behavior, and then to strengthen it.

4. Identification of goals associated with irrational attitudes. Rational goal setting.

5. Establishment of associations between irrational attitudes and disturbed eating behavior, evaluation of their truth and degree of adaptability.

6. Formation of new ways and principles of interpretation of Activating Events.

7. Fixing new ways of thinking.

The special techniques aimed at changing cognitive processes and their consequences are as follows: a technique determining the effect of thought on the feelings, thoughts and facts differentiation technique, a technique of estimation of emotion intensity and degree of belief in the truth of the thoughts, vertical descent technique, identification of beliefs and rules, damage and acquisitions analysis (Shamrei V.K., Kurpatov V.I., 2017. p.75-89) decatastrophizing, control of unwanted thoughts and feelings (stopthoughts), the conditioning of ideas and thoughts (latent conditioning), rearrangement of automated cognition (cognitive rearrangement) (A. Ellis 2000, p.256-276).

Here is an example of implementation of the technique of differentiation of thoughts and facts in a group of women with high BMI. To form a clear understanding of the semantics of concepts, a group discussion "Thoughts and Facts: General and Specific" is introduced. Further, each individually formulates one negative thought that arose during this day. Let us take a real example suggested by the participant of the group: the thought written by her: "All my fat is visible in this sweater". Next to this thought, the participant writes down the facts about this situation: "The sweater today protects me from cold. I have become slimmer and the sweater sits better than before. Today only children will see me in this sweater. The sweater is black and it hides fat better than blue. Is it fat at all?». The task of technique is to treat your thoughts as hypotheses, not allowing them to become convictions. An important element in the implementation of the technique is group discussion and assistance in the formulation of new facts.

An essential component of the work is a homework, the results of which are discussed in the group. An example of a homework is an analysis of 1-2 emotional events that occurred during the day using the $\mathrm{ABC}$ formula with $\mathrm{C}$ differentiation for the effects associated with feelings and the consequences associated with eating behavior.

Since a preliminary study has shown significant differences in the attitudes of obligation toward oneself and others between the groups with high and low BMI, then the implementation of RET techniques requires a flexible approach based on the revealed features. The group with low BMI has significantly high indices of obligation toward oneself that has led to special attention to awareness and identification of these attitudes, and the group with high BMI - to awareness and identification of obligation toward others. A significant difficulty at this stage was rigidity of these attitude systems and expressed psychological defense.

The change in attitudes of obligation was carried out by preliminarily written and then verbal fixing of the reformulated category "should" into the category "want". Changing semantics allows changing attitudes to life situations, expanding the repertoire of interpretation of goals. So, the attitudes of obligation toward oneself in the group of women with low BMI were, for example, restated on the variant: "I have to finish school with honors" through such an option as: "I want to prove to my parents that I can achieve something meaningful in this life" to the final version "I want my knowledge to help me develop in my profession". Thus, the transition from categorical and dogmatic obligation toward oneself to the wish opens up more alternatives in interpreting goals and variants of adaptive behavior.

Significantly higher attitudes of catastrophizing in groups with both high and low BMI dictated the need for using decathostrophizing techniques. One of the options for its implementation involves the analysis of actual events and their possible consequences, which are perceived as threatening. Using the strategy of the analysis of consequences "What if ..." allowed changing the opinionatedness in the assessment of events and reduce the psychoemotional tension by preparing oneself for these disturbing or frightening events. 
Low frustration tolerance as an irrational attitude manifests itself in the statements of women as the inability to endure any events of their life. Ellis suggests two ways to change this irrational attitude: a person must prove that this event cannot really be went through, and desentization in relation to situations that are perceived as catastrophic. Mastering the cognitive methods of rational thinking was carried out during group sessions, and mastering the methods of descentization served as the basis for home work followed by a group discussion of the results achieved. As a result of the use of RET, positive progress was revealed both with respect to the psychological characteristics of the respondents and with regard to the normalization of BMI (Table 3).

\begin{tabular}{|c|c|c|c|c|}
\hline \multirow{2}{*}{ Method } & \multirow{2}{*}{ Method scale } & \multicolumn{3}{|c|}{ Student $\mathrm{t}$-test } \\
\hline & & $\begin{array}{c}\text { Sample A } \\
\text { (normal BMI) } \\
\text { and B (deviating } \\
\text { BMI) post } \\
\text { therapy }\end{array}$ & $\begin{array}{c}\text { Sample B1 } \\
\text { (before therapy) } \\
\text { and B2 (post } \\
\text { therapy) }\end{array}$ & $\begin{array}{l}\text { Sample B1 } \\
\text { (before } \\
\text { therapy) and } \\
\text { B3 (6 months } \\
\text { post therapy) }\end{array}$ \\
\hline \multirow{3}{*}{$\begin{array}{l}\text { Dutch Eating Behavior } \\
\text { Questionnaire }\end{array}$} & Emotiogenic EB & $2.15 *$ & 2.96* & $2.31 *$ \\
\hline & Restrictive EB & 1.86 & $3.01 * *$ & 2.03* \\
\hline & External EB & 1.84 & $2.75 * *$ & $2.72 * *$ \\
\hline \multirow{7}{*}{$\begin{array}{l}\text { Eating Behavior } \\
\text { Assessment Scale }\end{array}$} & Desire for leanness & 1.48 & 2.45* & 2.34* \\
\hline & Bulimia & 1.63 & $2.56^{*}$ & 2.53* \\
\hline & Dissatisfaction with body & 2.04* & 2.84** & 2.43* \\
\hline & Inefficiency & 1.87 & 2.59* & $2.55 *$ \\
\hline & Perfectionism & 2.00 & $2.98 * *$ & $2.45 *$ \\
\hline & $\begin{array}{l}\text { Distrust in interpersonal } \\
\text { relations }\end{array}$ & 1.23 & $2.50 *$ & $2.46 *$ \\
\hline & Interceptive incompetence & 2.01 & $2.14 *$ & $2.13 *$ \\
\hline $\begin{array}{l}\text { Express diagnosis of } \\
\text { LN }\end{array}$ & Level of neuroticism & $2.65 *$ & $2.35 *$ & 2.31* \\
\hline \multirow{9}{*}{$\begin{array}{l}\text { Diagnostics of } \\
\text { typologies of } \\
\text { psychological defense }\end{array}$} & Negation & 1.98 & $2.81 * *$ & $2.46^{*}$ \\
\hline & Repression & 1.87 & 1.82 & 1.84 \\
\hline & Regression & 2.59* & $2.33^{*}$ & 1.93 \\
\hline & Compensation & 1.68 & 3.01** & 2.78* \\
\hline & Projection & 1.89 & 1.95 & 1.93 \\
\hline & Substitution & 1.87 & $2.59 *$ & 2.61* \\
\hline & Intellectualization & 1.23 & 2.01 & 2.00 \\
\hline & Reactive formations & $2.45 *$ & $2.49 *$ & 2.50* \\
\hline & $\begin{array}{l}\text { Index of intensity of } \\
\text { psychological defenses }\end{array}$ & 1.94 & $2.18 *$ & $2.61 *$ \\
\hline \multirow[t]{2}{*}{ Body ego diagnostics } & $\begin{array}{l}\text { Self-acceptance of the image } \\
\text { of the body ego }\end{array}$ & 1.44 & $2.45 *$ & $2.41 *$ \\
\hline & $\begin{array}{l}\text { The influence of the other on } \\
\text { the attitude toward the image } \\
\text { of the body ego }\end{array}$ & 1.52 & $2.53 *$ & $2.58 *$ \\
\hline \multirow{6}{*}{$\begin{array}{l}\text { Methods of diagnosing } \\
\text { irrational attitudes }\end{array}$} & Catastrophizing & $2.63 *$ & $2.38 *$ & 1.64 \\
\hline & Obligation toward oneself & 1.33 & $2.91 * *$ & 2.58* \\
\hline & Obligation toward others & 1.24 & $2.47 *$ & 2.38* \\
\hline & Low frustration tolerance & 1.34 & $2.51 *$ & 2.49* \\
\hline & Self-assessment & 1.79 & 1.92 & 1.82 \\
\hline & & $\begin{array}{l}* t_{t}=2.02 \\
\mathrm{p} \leq 0.05 \\
* * t_{t}=2.69 \\
\mathrm{p} \leq 0.01\end{array}$ & $\begin{array}{c}* t_{t}=2.02, \mathrm{p} \leq 0.05 \\
* * t_{t}=2.69 \\
\mathrm{p} \leq 0.01\end{array}$ & $\begin{array}{c}* t_{t}=2.02 \\
\mathrm{p} \leq 0.05 \\
* * t_{t}=2.69 \\
\mathrm{p} \leq 0.01\end{array}$ \\
\hline
\end{tabular}

Table 3: The Results of Psychotherapy of Eating Disorders 
The comparison of BMI in the experimental group before and after psychotherapy shows its normalization both in the sample with low (sample D) and with high (sample C) BMI. So, immediately after the completion of work on the program in sample C, the BMI decreased significantly $\left(t_{t}=3.87\left(t_{t}=2.80\right.\right.$, $\mathrm{p} \leq 0.01)$ ), with this trend remaining after six months $\left(t_{t}\right.$ $\left.=3,98\left(t_{t}=2.80, \mathrm{p} \leq 0.01\right)\right)$. In sample $\mathrm{D}$, a statistically significant change in the BMI is also observed: immediately after therapy $\left(t_{t}=2.59\left(t_{t}=2.06\right.\right.$, $\mathrm{p} \leq 0.05))$, and after six months $\left(t_{t}=2.52\left(t_{t}=2.06\right.\right.$, $\mathrm{p} \leq 0.05)$ ).

The comparative analysis of the final results showed the following dynamics: the indices of the sample B approached sample A for restrictive EB and external $\mathrm{EB}$, while there remain statistically significant differences between these samples for emotiogenic $\mathrm{EB}$, which indicates that this type of eating behavior is the most stable. At the same time, the dynamics of indicators within sample B immediately after therapy turned out to be positive and showed statistically significant changes in all three types of eating behavior. However, six months after the completion of therapy, some participants (about 10\%) began to show certain signs of eating disorders in emotional and restrictive types, which may indicate both the stability of these types of eating behavior and the lack of thoroughness of psychological influences. Against this backdrop, the successes of participants with external EB have become especially noticeable, which allows us to judge the maximum effectiveness of the program in relation to this type of eating behavior.

Respondents in the sample B were statistically close to sample A in terms of the following indicators: dissatisfaction with the body, inefficiency, perfectionism, interoceptive incompetence, level of neuroticism, negation, regression, compensation, substitution, reactive formations, self-acceptance of the image of the body ego, the influence of the other on attitude towards the image of the body ego, obligation toward oneself and others, low frustration tolerance. The sample B showed statistically significant changes occurred after the completion of therapy in terms of the following indicators: desire for leanness, bulimia, dissatisfaction with the body, inefficiency, perfectionism, lack of confidence in interpersonal relationships, interoceptive incompetence, level of neuroticism, negation, regression, compensation, substitution, reactive formations, self-acceptance of the image of the body ego, obligation toward oneself and others, low frustration tolerance.

Six months after the completion of the program, the sample B had expressiveness in the following indices: regression and catastrophizing; and a slight negative dynamics in respect of satisfaction with the body, perfectionism, negation, compensation, and obligation toward oneself.

The results obtained made it possible to make adjustments to the content of the program: this is understanding and identification of family traditions and stereotypes of eating behavior; expansion of the repertoire of techniques in relation to the most stable and rigid characteristics of persons with eating disorders.

\section{Summary}

In general, the developed program has shown its effectiveness. Its completion has led to normalization of BMI in women with eating disorders and abnormal body weight.

The overwhelming majority of participants in the program to some extent got rid of extreme forms of pathological eating behavior and approached an adequate option; they began to more constructively perceive and accept their body, reduced the intensity of the painful desire for excessive leanness, learned to control bouts of gluttony, cope with emotional shocks in more productive ways; worked on the interpersonal relations and attitudes to themselves, and their own effectiveness in society; formed the ability to analyze bodily sensations, recognize and differentiate the true and false motivations for eating.

The participants of the project have learned to recognize and analyze their psychological defenses and to move to conscious management of their behavior. The position of being obliged has changed to a more rational way, frustration tolerance increased, the participants became less receptive to the opinions of others about themselves and their appearance.

Despite the general positive dynamics, we see that with respect to some women and girls, the stability of the irrational attitude of catastrophizing and psychological defense of regression is observed. Both parameters belong to the sphere of the unconscious and require in-depth specialized psychological help. For some women, the emotional nutritional response to stress and failure remains relevant. The use of additional techniques and the possibilities of RET in relation to catastrophizing will make it possible to more effectively influence the emotiogenic EB. The participants with restrictive EB require additional work on their self-assessment, acceptance, the balance of the "real ego" and "ideal ego", and the formation of stereotypes of healthy eating behavior.

\section{Conflict of Interests}

The authors declare that the provided information has no conflicts of interest.

\section{References}

1. Bazhenova N.G., Shpakovskaia E.Iu., Zimareva T.T., Stepanova O.P., Shuleva E.I. Psychology of official business: a course of lectures. Magnitogorsk, 2015. p. 161 [in Russian].

2. Voznesenskaia T.G., Safonova V.A., Platonova N.M. Eating disorders and comorbid syndromes in obesity and methods of their correction // S.S. Korsakov Journal of Neurology and Psychiatry. 2000. No. 12. p.49-52. [in Russian].

3. Gavrilov M.A. The correlation of psychological and physiological characteristics in normalizing body weight in women with excess weight. Author's abstract., PhD Medicine. Tomsk. 1999. p.24. [in Russian]. 
4. Gurevich I.N. Social psychology of health. Author's abstract, PhD Psychology. St. Petersburg. 1997. p. 57. [in Russian].

5. Ilchik O.A. Russian-language adaptation of the methodology "Eating Behavior Assessment Scale" // Psychiatry, psychotherapy and clinical psychology. 2011. No. 1. p. 39-50. [in Russian].

6. Kameniukin A.G., Kovpak D.V. Anti-stress training. St. Petersburg. 2008. p. 224. [in Russian].

7. Korkina M.V., Tsivilko M.A., Kareva M.A. Stages of rehabilitation of patients with anorexia nervosa // Social and Clinical Psychiatry. 1993. No.1. p. 84-96. [in Russian].

8. Kultyshev D.V. Clinic, dynamics and the diagnosis of borderline disorders in adolescents with dependent eating behavior. Author's abstract, Phd Medicine. Tyumen. 2010. p. 24. [in Russian].

9. Lowen A. Bioenergetics (the revolutionary new therapy that uses the language of the body to heal the problems of the mind) / trans. from English. St.P. 1998. p. 382. [in Russian].

10. Lybko I.V. The technique of diagnosing the body ego // Psychological diagnostics, 2008. No.3. p. 5-21. [in Russian].

11. Malkina-Pykh I.G. Eating behavior therapy. M. 2007. p. 1040. [in Russian].

12. Markov A.A. Borderline neuropsychiatric disorders with excess weight and obesity. Author's abstract, PhD Medicine. - Tomsk, 2006. p. 23. [in Russian].

13. Workshop on social psychology / E.Iu. Shpakovskaia, O.P. Stepanova, N.G. Bazhenova, T.T. Zimarev, M.V. Kostiuchenko. Magnitogorsk. 2007. p. 164. [in Russian].

14. Prilenskaia A.V. Analysis and rehabilitation of persons with dependent eating behavior // Siberian Bulletin of Psychiatry and Addiction medicine. 2006. Appendix (41). p. 228-229. [in Russian].

15. Prilenskaia A.V. A system approach in the psychotherapy of borderline disorders / B.Iu. Prilenski, A.V. Prilenskaia, M.A. Bogdanovich, I.I. Fedorova, D.V. Kultyshev, I.V. Ovchinnikova, S.O. Sazonov // Monitoring of mental health. Materials of the interregional scientific and practical conference. Tomsk; Novokuznetsk. 2006. p. 139-143. [in Russian].

16. Prilenskaia A.V. Boundary neuropsychiatric disorders in patients with dependent eating behavior (clinical and rehabilitation aspect). Author's abstract, PhD Medicine. Tomsk. 2009. p. 163. [in Russian].

17. Psychotherapy: a textbook / ed. V.K. Shamrei, V.I. Kurpatov. St. Petersburg. 2017. p. 501. [in Russian].

18. Rotov A.V. Dependence of the decrease in overweight in the process of psychotherapeutic correction on the hypnosis of patients // Siberian Bulletin of Psychiatry and Addiction medicine. 2000. No.4. p. 69-71. [in Russian].

19. Rybalko M.I. Multimodal bodily-oriented psychotherapy in the treatment of anorexia nervosa // Current aspects of psychosomatic research. Tomsk. 2005. p. 166-168. [in Russian].
20. Sidorov A.V. Eating behaviors and psychological characteristics of the clients of weight loss program with alimentary obesity. Author's abstract, PhD Psychology. St.P., 2012. p. 26. [in Russian].

21. Skugarevskii O.A. Eating disorders: monograph. Minsk. 2007. p. 340. [in Russian].

22. Taton Ia. Obesity: pathophysiology, diagnosis, treatment. M. 2008. p. 23. [in Russian].

23. Tokar O.V., Shpakovskaia E.Iu. Psychoprophylaxis and psychocorrection of addictive behavior. Development of corrective-prophylactic programs: [Electronic resource]: educationalmethodical manual. Magnitogorsk. 2016. 1.82 MB. [in Russian].

24. Tumbasova E.R. Analysis of the concept of "food behavior" // Modern trends in the development of science and technology. 2017. No.3-9. p. 130-133. [in Russian].

25. Fedorova I.I. Clinical-dynamic and psychotherapeutic aspects of eating disorders. Author's abstract, PhD Medicine. Tomsk. 2007. p. 23. [in Russian].

26. Fetiskin N.P., Kozlov V.V., Manuilov G.M. Socio-psychological diagnosis of personality and small groups. M. 2002. p. 490. [in Russian].

27. Ellis A. A revision of the fundamentals of rational-emotive therapy // Evolution of psychotherapy: Collection of papers. V.2. Autumn of the Patriarchs: psychoanalytically oriented and cognitive-behavioral therapy / Ed. J.K. Zeig/ Trans. from English. M.1998. p. 416. [in Russian].

28. Ellis A. Rational psychotherapy // Techniques of psychotherapy and counseling. Texts / ed. and comp. U.S. Sakhakian / trans. from English. M. 2000. p. 256276. [in Russian].

29. Iaremenko L.N. Psychoemotional correction in the integrated treatment of obesity // Family doctor. 2002. No.2. p. 35-39. [in Russian].

30. Beck A.T. Cognitive therapy and the emotional disorders. $\quad$ - N New-York: International Universities Press, 1976. p. 356 [in English].

31. Geist R, Heineman M, Stephens D Et al. Comparison of family therapy and family group psychoeducation in adolescents with anorexia nervosa. Can J Psychiatry 2000. P. 173-178 [in English].

32. Ellis A.A. Overcoming Destructive Beliefs, Feelings, and Behaviors: New Directions for Rational Emotive Behavior Therapy; Prometheus Books. 2001. 419 p. [in English].

33. Merphy R., Straebler S., Cooper Z. Cognitive behavioral therapy for eating disorders // Psychiatrie Clinics of North America. - 2010. - № 33(3). - P. 611627. [ in English].

34. Minuchin S. Rosman B.L. \& Baker L. Psychosomatic families" Anorexia Nervosa in context. Cambridge, MA: Harvard University Press. 1978. p. 315 [in English] 